\title{
Presencias enrevesadas: los cuerpos/emociones que acompañan a los/as usuarios/as de drogas en los tratamientos ambulatorios*
}

*Fecha de recepción: 27 de julio de 2016. Fecha de aceptación: marzo de 2017.

Ana Laura Candil $* *$

** IIGG-FSOC-UBA UNPaz / CONICET

\section{Resumen}

A partir de una investigación guiada por el enfoque etnográfico, este artículo busca aportar al esclarecimiento las complejidades vinculares y corporales/emocionales implicadas en el acompañar a los/as usuarios/as de drogas de mala calidad en los tratamientos ambulatorios públicos desplegados en un barrio empobrecido del Área Metropolitana de Buenos Aires. Para ello se detiene en: la modalidad de sinécdoque que adquiere la convocatoria a la familia; algunas lecturas expertas sobre las modalidades de vinculación entre las mujeres-madres para con los/as usuarios/as; y las afecciones que atraviesan a las mujeres durante el proceso de acompañar a otros/as que usan intensivamente sustancias y que forman parte de las poblaciones desfavorecidas urbanas.

\footnotetext{
Abstract

From an investigation led by the ethnographic approach, this article seeks to contribute to clarify the relational and body / emotional involved in supporting users drugs of poor quality in public outpatient treatments deployed in an impoverished neighborhood the Metropolitan Area of Buenos Aires. For it stops in: the synecdoche mode that acquires call the family; some experts readings on the modalities for linking women - mothers with user ; and conditions that women go through during the process of supporting others that intensively use substances and are part of the urban disadvantaged populations.
}

\section{Palabras clave:}

cuerpos/emociones, usos de drogas, tratamientos ambulatorios, redes de proximidad.
Keywords:

bodies/emotions, use of drugs, outpatient treatment, proximity networks. 


\title{
Introducción
}

\author{
"Una cinta de Moebius a la que se sobrevive -y en la que \\ se interviene-con valores que no tienen que ver con la \\ condición femenina, sino con la resistencia física y psíquica \\ a la miseria y sus infinitas circunstancias".
}

Josefina Licitra

Un miércoles frío de agosto del año 2012, pasado el mediodía, vi llena la sala de espera de una institución pública de tratamiento para los usos intensivos de drogas y no me sorprendí. A las 14:30 h funcionaba el grupo de admisión y, en paralelo, el grupo de familiares: era el día que más personas había en ese centro de salud localizado en un barrio empobrecido del Área Metropolitana de Buenos Aires (en adelante AMBA). Mujeres y varones aguardaban sentados en las sillas de plástico blancas de esa sala con machimbre barnizado en las paredes. La mayoría de los varones pasarían al grupo de admisión. Algunos pocos tendrían entrevistas individuales, mientras que algunas mujeres los esperarían. La mayoría de las mujeres y un varón pasarían a un salón grande, todos juntos, con sillas dispuestas en un círculo en el que, durante dos horas, hablarían con una psicóloga y una operadora socio-terapéutica sobre lo que los preocupaba y ocupaba: el consumo intensivo de drogas por parte de sus hijos y/o parejas. La mayoría de las mujeres acompañaban -en las consultas, en el grupo de familiares, en la cotidianidad de sus vidas- a los/as usuarios en los tratamientos para reducir y/o descartar el uso intensivo de drogas y, según los profesionales de la salud, esto implicaba una esperanza en el tránsito hacia cierto bienestar.

Poco tiene de novedoso que las mujeres acompañen en los tratamientos de salud. Ya ha sido documentado que los servicios e instituciones tienen mayores barreras de accesibilidad para con ellas, aún más cuando de usos intensivos de drogas se trata (Epele, 2010). Y, también, ya han sido reiteradamente problematizadas las vinculaciones entre género y cuidado. Sin embargo, la intersección entre género, emociones, tratamientos y usos de drogas en poblaciones desfavorecidas no ha tenido un lugar preponderante en los análisis, incluso cuando algunos discursos hicieron de las familias una suerte de piedra de toque de algunas explicaciones como si fueran inmutables a los cambios económico-políticos de las últimas décadas, o como si las dinámicas familiares fueran causa y solución de los padecimientos implicados en las ingestas intensivas de sustancias -especialmente de la pasta base/paco- (Castilla, Olsen y Epele, 2012). Diversos autores han documentado en el AMBA que algunos de los efectos del proceso de neoliberalización (Harvey, 2009), iniciado en la década de 1970 y profundizado en la década de 1990 en la Argentina, han sido el acrecentamiento de la pobreza, el progresivo encierro territorial, la minuciosa perpetración policial en los barrios, la expansión de cocaínas fumables y los cambios en los códigos que antaño tenían un carácter regulador en las transacciones de bienes, servicios y afectos. Y que estas mutaciones -que han impactado fuertemente en la cotidianidad de la vida de las poblaciones desfavorecidas-, modelaron las prácticas de cuidado a otros. Y que, cuando las drogas median la cotidianidad, las lógicas de violencia, criminalización y psico-medicalización de los problemas sociales se profundizan (Kessler, 2008; Epele, 2010; Auyero y Berti, 2013; Epele, 2012; Castilla, Olsen y Epele, 2012; Murillo, 2013).

A diferencia de aquellas perspectivas que orientan los análisis de los tratamientos de salud a las prescriptivas de los/as profesionales sobre los/as usuarios/as, mi interés estuvo centrado en analizar la urdimbre de los tratamientos ambulatorios: la dinámica terapéutica y la cotidianidad de la vida en la que se despliega, ya que al no implicar residencia institucional (como en el caso de las comunidades terapéuticas y/u hospitalizaciones) los tratamientos se apoyan en el espacio habitado y en la continuidad de 
los vínculos próximos. Esta consideración me llevó a analizar, entre otras dimensiones, los tratamientos desde la carnadura vincular situada que los condiciona y posibilita: las interacciones entre los/as profesionales de la salud, los usuarios/as de drogas y sus redes de proximidad. En este

o me centro en una arista que ha sido poco explorada en las producciones nacionales e internacionales sobre esta temática: las afecciones que atraviesan las redes de proximidad y algunas decodificaciones que realizan los/as profesionales de la salud sobre dichas afecciones y sobre los vínculos en las que se despliegan. Este artículo, entonces, busca colaborar a esclarecer, desde una perspectiva etnográfica, los cuerpos/emociones de quienes acompañan -usualmente nominados familiares- a los/ as usuarios/as intensivos/as de drogas de las poblaciones desfavorecidas y ciertas lecturas expertas sobre las modalidades vinculares que sustentarían las mismas en los tratamientos psicoterapéuticos ambulatorios públicos que se despliegan en un barrio empobrecido del AMBA. Para ello, me detengo en la perspectiva metodológica que orientó la investigación. Luego, sugiero que la convocatoria a la familia desde los tratamientos funciona como una sinécdoque. ${ }^{1}$ Brevemente, sitúo al proceso de acompañar en los tratamientos ambulatorios. Posteriormente, expongo algunas de las lecturas expertas sobre el papel y las modalidades de vinculación entre quienes acompañan y los/as usuarios/as de drogas. Después, me detengo en las afecciones relatadas por las mujeres que despliegan el papel de acompañantes. Y, por último, recapitulo lo expuesto.

\section{Perspectiva metodológica}

Para realizar la investigación en la que se enmarca este artículo, ${ }^{2}$ me guié por el enfoque etnográfico (Achilli, 2005 y Guber, 2012) y tuve el objetivo general de analizar los tratamientos públicos ambulatorios de salud sobre los/as usuarios/as intensivos/as de drogas en el AMBA, contemplando tanto la dinámica terapéutica como la cotidianidad de la vida en la que se despliega. Realicé el trabajo de campo durante dos años (2012-2013), principalmente en una institución pública de salud, ambulatoria, profesionalizada, interdisciplinaria y especializada en consumos problemáticos, localizada en un barrio empobrecido del AMBA con casi dos décadas de trayectoria de intervención, a la que llamaré "El Punto".

Las técnicas de producción de datos fueron principalmente las observaciones participantes. En El Punto, observación de: grupos terapéuticos, grupos de familiares, sala de espera, entrevistas institucionales, vereda de la institución, reuniones de equipo, jornadas de capacitación, jornadas hospitalarias, mesas de gestión barrial; también visité tres barrios en los que habitan parte de los jóvenes y adultos que realizan tratamientos en El Punto (y, en algunos casos que fui invitada, asistí a sus viviendas). Además, llevé a cabo casi una treintena de entrevistas semi-estructuradas y/o en profundidad a sujetos mayores de dieciocho años: once a profesionales de la salud -psicólogos, trabajadoras sociales y operadores socio-terapéuticos-, trece a jóvenes y adultos que usan intensivamente drogas de mala calidad y que realizan tratamientos ambulatorios (con una media de edad de treinta años), cuatro a sus redes de proximidad -madres y parejas-; y una a un referente social. Las entrevistas fueron grabadas, transcriptas, y analizadas sin la utilización de software. Las observaciones participantes y las entrevistas fueron registradas en notas de campo. Por medio de estas técnicas, elaboré cuarenta y tres casos. Resulta importante señalar que solo dos de los usuarios contactados fueron mujeres y que cuarenta y uno fueron varones. La investigación fue evaluada y avalada por el Comité de Ética del Instituto Gino
1 Según la Real Academia Española, sinécdoque hace referencia a la "designación de una cosa con el nombre de otra (...), aplicando al nombre de una de sus partes".
2 Esta investigación, asentada en el Instituto de Investigaciones Gino Germani (FSOC-UBA), fue realizada en el marco del Doctorado de Ciencias Sociales de la Universidad de Buenos Aires, tuvo como resultado mi tesis doctoral y fue financiada por el Consejo Nacional de Investigaciones Científicas y Técnicas (CONICET). 
Germani, adecuándose a los recaudos que regulan las investigaciones en salud. A fin de resguardar la identidad de los participantes, modifiqué sus nombres.

\section{Una usual sinécdoque: la familia}

Siguiendo a Tronto (1993), en la respuesta a la pregunta “¿Quién cuida a quién?” puede advertirse la estructura de dominación y subordinación de una sociedad determinada, ya que allí se engarzan configuraciones morales, políticas y económicas. La producción académica en torno del cuidado, señala que las prácticas enmarcadas en esta noción son desvalorizadas debido a que se las vincula al mundo privado, afectivo y emocional, y a la necesidad; y que quienes cuidan suelen ser mujeres, migrantes y/o pobres -o la conjunción de todas estas segmentaciones poblacionales- (Tronto, 1993; Mol, 2008; Jelín, 2010; Domínguez Mon, 2012; Pautassi y Zibecchi, 2013; Epele, 2013). Al ser las prácticas de cuidado desvalorizadas socialmente, lo son también quienes las realizan, conllevando asimismo -en el caso de que se encuentren remuneradas- salarios bajos. Los dominios en los que el cuidado opera son sumamente heterogéneos: trabajo doméstico, crianza de niños, prácticas de salud abordadas desde la enfermería, la terapia ocupacional y el trabajo social, la atención a enfermos y discapacitados, etc. Si bien las características antes mencionadas operan en la totalidad de los dominios del cuidado, en lo que se delimita como cuidado en salud, adquieren especificidades debido a que se centran en el ámbito de atención a los malestares y dolores (Ayres, 2004; Kleinman, 2004; Bonet y Tavares, 2007; Epele, 2012).

En diálogo con -y siguiendo a- estas producciones, en la respuesta de la pregunta "¿Quién acompaña a quién en los tratamientos ambulatorios públicos?" también es posible identificar la estructuración de una sociedad y, según lo que se ha podido identificar en el trabajo de campo, pueden advertirse deslizamientos desde las terapéuticas hacia lasfamilias. Sin embargo, quienes acompañan -y asisten a El Punto a revisar ese acompañamiento- son, en su amplia mayoría, mujeres. Es por esto que no deja de ser atinada la caracterización sobre las políticas sociales abonando la desigual división y distribución sexual del trabajo: diversas investigaciones han esbozado que la familia funciona como una sinécdoque que vela la delegación de las prácticas de cuidado a las mujeres (Schwarz, 2012; Navarro y Rico, 2013). Esta caracterización general cobra importancia, ya que los tratamientos públicos se enmarcan en la política social que conforma el sistema público de mantenimiento de la fuerza de trabajo en el modo de producción capitalista -es decir, forma parte del conjunto de servicios y bienes que no son provistos por el salario y que, sin embargo, son necesarios para la reproducción de la clase trabajadora- (Topalov, 1979). Estudios específicos sobre la noción de cuidado han demostrado que gran parte de la protección social en Latinoamérica es de resolución privada y que las prácticas de cuidado implican valor económico, ya que son necesarias para la reproducción social-todos necesitamos que nos cuiden en algún momento de nuestras vidas y las tareas implicadas en el proceso de cuidar no siempre se encuentran asalariadas, no se invisten en la forma de empleo- (Aguirre, 2005; Rodriguez Enriquez, 2012; Navarro Rico, 2013; Castilla, 2013; Voria, 2015).

Los tratamientos ambulatorios públicos sobre los consumos problemáticos de drogas no son la excepción: quienes mayoritariamente acompañan -no solo durante el tratamiento-a los/as usuarios/as de drogas son mujeres-madres o parejas en su mayoría.

La idea euro-occidental de familia, específicamente de familia nuclear, deviene de la diferenciación del mundo público -lo racional, la esfera de la producción, el empleoy el mundo privado -lo emocional, la esfera de la reproducción, la domesticidad- en paralelo al-y como requisito de-el capitalismo industrializador (Torrado, 2007). Esta 
disociación entre domesticidad y empleo tiene como correlato una particular división sexual del trabajo dentro y fuera de la vivienda habitada. En el orden patriarcal idealmente-, los varones son quienes salen a trabajar y las mujeres son quienes están a cargo de la casa (Durham, 1998). Si bien esta caracterización, ya clásica, posibilita historizar la conformación de este modelo de familia, no se dio del mismo modo en todas las regiones ni, mucho menos, en todas las fracciones poblacionales (Fonseca, 2007). Por un lado, en los sectores populares -al menos latinoamericanos-, las mujeres trabajan desde al menos unas cinco décadas, dentro y fuera del ámbito doméstico (Torrado, 2007 y Jelín, 2010). Por otro lado, la visualización jurídica y social de las para nada nuevas dinámicas familiares ponen en jaque constante a aquella prescripción de la familia nuclear (Stolkiner, 2004; Jelín, 2010; Tarducci, 2013; Maffia, 2014). ${ }^{3} \mathrm{La}$ crítica feminista y marxista, además, cuestiona la disociación entre domesticidad y empleo, a partir de dos argumentos centrales. Por un lado, el trabajo doméstico -al interior del hogar-tiene valor económico, aunque no se asalarice directamente en todos los casos, siendo parte -necesaria en la modalidad capitalista de producción- de la reproducción ampliada de la fuerza de trabajo (Pautassi y Zibecchi, 2013 y Tarducci, 2013). Por otro lado, las relaciones de género -entendiendo a estas como relaciones de dominación- entrelazan domesticidad, cuidado y rol de la mujer (Durham, 1998; Fuller, 2001; Torres Dávila, 2004). Es decir, las mujeres trabajan y, además, cuidan a los niños y enfermos. Diversos estudios que abordan la noción de cuidado y la construcción socio-cultural de la maternidad (Shepper Hugges, 1997; Palomar Veréa, 2005; Castilla, 2013) señalan que sobre las mujeres-madres recae el imperativo moral del cuidado, ya que la "buena maternidad" condensa el ideario -engarzado con la idea de "hecho natural" y/o "instinto materno"- del "amor incondicional hacia los hijos, la entrega de tiempo y recursos, la postergación de los proyectos personales y la vigilia constante para que los hijos logren ser seres felices y competentes, [estas] son dimensiones que se encuentran estructuradas y que, a la vez, estructuran las prácticas y normativas maternales y los sentidos atribuidos al ser mujer" (Castilla, 2013: 210).

El imperativo moral de hacerse cargo de la domesticidad que recae -no sin conflictosobre las mujeres, no deja de operar -en tanto lógica de dominación y/o subordinación- aunque sea criticado analítica y políticamente (Fuller, 2001; Fonseca, 2007; Jelin, 2010). Las perspectivas de los/as profesionales de El Punto, al menos discursivamente, no abonan una concepción clásica de familia reducida al núcleo familiar que comparte residencia, sino que abona la inclusión de otros significativos (amigos/as, tíos/as, vecinos/as, etc.). Sin embargo, es necesario hacer algunas aclaraciones. Por un lado, desde la decodificación de los saberes psi, las funciones maternas y paternas son constituyentes de los sujetos y adquieren valoración diferencial respecto de otros roles. Por otro lado, el ensanchamiento de la noción de familia hacia otros/as significativos/as pareciera más un anhelo de contar con otros/as, de incluir a más personas en las redes de contención y dinámicas familiares, que una materialidad cotidiana. Detengámonos brevemente, entonces, en lo que implica acompañar a usuarios/as intensivos/as en los tratamientos públicos ambulatorios.

\section{Breve comentario acerca del acompañar en los tratamientos ambulatorios}

La mayoría de los jóvenes y adultos que usan sustancias con quienes me vinculé durante el trabajo de campo, según han manifestado, consumen intensivamente cocaínas de mala calidad. ${ }^{4}$ Casi en su totalidad habitan en sectores empobrecidos de la cuidad (barrios precarios, villas y/o asentamientos), no han terminado la escolaridad media, se sustentan mediante empleos informales (que van desde pintura y albañilería, hasta la mendicidad) y han habitado espacios de encierro (cárceles, comisarías, institutos de menores, hogares de niños, etc.). A su vez, cuentan con recursos para acceder
3 En la Argentina, en los últimos 6 años, se ha sancionado la Ley de Matrimonio Igualitario, la Ley de Identidad de Género y se ha reformado el Código Civil.
4 Me refiero a cocaínas de mala calidad (en plural), ya que las múltiples sustancias incluidas en esta nominación se diferencian en: calidades y precios -a menor calidad, menor precio-, diferentes formas de administración -inhalables, fumables e inyectables-; $y$, bajo iguales nominaciones (cocaína), confluyen una diversidad de productos (cocaína base, pasta base/paco, clorohidrato de cocaína, etc.). Siguiendo las perspectivas locales, no se trata siempre de la misma pasta base/paco ni del mismo clorohidrato de cocaína, debido a que se diferencian en función de la calidad de la materia prima y de los diversos productos con los que es mezc "rebajada" "estirada" Desde la perspectiva de los jóvenes y adultos usuarios en tratamiento con quienes me vinculé en el trabajo de campo, las cocaínas a las que acceden - clorohidrato de cocaína, pasta base/ paco- son de mala calidad. Para adentrarse en diversos debates acerca de la emergencia y expansión de cocaínas de mala calidad en América Latina, se sugiere la lectura de la producción de Castaño (200o), Touzé (2006), Epele (2010), entre otros. 
a las terapéuticas: saber que existen, que son gratuitas, estar situados en tiempo y espacio, recordar que tienen que ir o tener alguien que se los recuerde, tener dinero para trasladarse, entre otros. Las mujeres que los acompañan en el tratamiento ambulatorio comparten las precarias condiciones de vida y son en muchas ocasiones sus redes de sostén.

Los tratamientos que se despliegan en El Punto se sustentan en la permanencia en el espacio habitado y la continuidad de los vínculos próximos (de parentesco, amistad y enemistad). La dinámica terapéutica inicia cuando los sujetos -usuarios y/o familiares - se acercan a la institución y prosigue -en caso de que continúen asistiendo- en entrevistas con profesionales de la salud. A grandes rasgos se trata de entrevistas individuales y/o grupales semanales de los pacientes con psicólogos (de entre media y una hora de duración en caso de las individuales y de dos horas en el caso de las grupales) y en menor medida talleres, orientaciones sociales e interconsultas psiquiátricas. Además, se desarrolla un grupo de familiares coordinado por una psicóloga y una operadora socio-terapéutica, cuyo objetivo es rondar sobre lo que sienten, hacen y/o dejan de hacer -prioritaria y mayoritariamente- las mujeres relacionadas a través de vínculos próximos (de consanguinidad y/o afiliación) con los usuarios: quienes los acompañan.

Acompañar a usuarios intensivos de drogas requiere de disposiciones, competencias y prácticas que no son necesariamente requeridas cuando las drogas no problematizan la cotidianidad. Como todo, el acompañamiento - y los cuerpos/emociones implicados en su desarrollo- se despliega situado en los procesos económico-políticos-culturales que lo requieren y posibilitan. Una amplia multiplicidad de tareas se engloban en esta noción que aglutina aspectos del cuidado, la protección y el control. Algunas de las prácticas implicadas en el acompañamiento -y que han sido desarrolladas detenidamente en otro trabajo (Candil, 2016)- son: elaboración de alimentos, limpieza del hogar, organización de la economía doméstica, cuidado de los niños, ir a comprar drogas, habilitar su uso en las viviendas habitadas, evitar y/o convocar a la policía ante conflictos con pares, vendedores de drogas y/o vecinos, otorgar dinero para la compra de sustancias, escoltar en los tratamientos, realizar reiterados llamados telefónicos y enviar mensajes de textos para saber dónde se encuentran sus seres queridos, irlos/as a buscar en las noches a los espacios en los que se encuentran, entre tantas otras. Como puede intuirse, las afecciones que conllevan la realización de estas tareas implican rispideces y densifican la cotidianeidad de la vida de los/ as usuarios/as intensivos/as y de quienes los quieren y pueden estar con ellos en el proceso de amainar y/o descartar la ingesta de drogas.

\section{De abandonos y pegoteos: lecturas expertas sobre el papel de las mujeres}

En correspondencia con los análisis acerca del cuidado, algunas versiones de los profesionales de la salud decodifican la prevalencia de mujeres en la función de acompañantes en relación con las coordenadas de la división sexual del trabajo al interior de las familias:

Me parece que en general a la mujer se le adjudica el rol de cuidadora, de responsable también de que el pibe llegue a una consulta, o porque el padre está trabajando, o porque en esas cosas no se mete, o porque no hablan, o porque tienen un problema de consumo, o porque son agresivos... se les adjudica distintas cosas a los varones me parece, adultos. (Melisa, trabajadora social) 
La prevalencia de las madres dentro del conjunto de las mujeres en la función de acompañantes es registrada y decodificada por los trabajadores de la salud de diferentes maneras. Algunas de las versiones de los profesionales diferencian dos tendencias generales y opuestas en la modalidad de relación que se establece entre madres e hijos: el "pegoteo" y el "abandono":

-No sé si como manera universal, yo creo que para mí debe haber puntos medios, pero a grandes rasgos hay así como un pegoteo madre-hijo en general, porque también puede ser madres-hijas o padres-hijas, o como un pegoteo familiar o un abandono total. A mí esas dos situaciones me angustian bastante. Más que... como decir está todo ahí pegado, el pibe no puede hacer otra cosa, no puede pensar, no puede accionar, está todo ahí pegado. Con todo el amor del mundo por ahí... y por el otro lado ves situaciones de abandono total, descuido.

-¿Cómo qué?

-Situaciones de agresión de la familia a un hijo que decís eso es descuido total, abandono, el ser humano de manera integral está totalmente vulnerado en un montón de aspectos... un chico con una historia re cruda, de abuso, de abandono, de no tener documento, no comer, un abandono a un niño... (Melisa, trabajadora social y Lucía, operadora socio-terapéutica)

Los profesionales que tienen una formación por fuera de los saberes psi-operadores socio-terapéuticos y trabajadoras sociales- promueven acciones y escuchas que intentan sostener una posición de no-responsabilización de los padecimientos de los usuarios de drogas hacia sus madres. Quienes han sido formados académicamente en los saberes psi, en la crítica a la división sexual del trabajo y en las funciones al interior de las familias suelen ser velados bajo la decodificación de las relaciones vinculares en torno del "buen o mal desempeño del rol materno"-en los casos más extremos- y del despliegue de "la madre suficientemente buena" -en las versiones menos tajantes-.

Independientemente de la formación de los profesionales, la construcción de lo que debieran ser "las madres" y/o "el rol materno"-desde los saberes expertos- no deja de estar ligado a los tópicos de pureza, virtud, amor y baluarte moral (Schwarz, 2007). Incluso cuando se establece una revisión de esos tópicos. Tal es el caso de la crítica a "la posición de la madre abnegada", que desde los saberes expertos, sería el prototipo de la madre que "genera vínculos de pegoteo":

- Esta cosa de la madre... que todo lo puede y que tiene que dejarlo todo... La verdad que tampoco la beneficia a la mujer. Esto también lo he visto y lo escucho... de la madre abnegada que deja todo por los hijos... Está bien, se joroba la vida, pero también en un punto creo que les perjudica la vida a los hijos, porque ¿viste?... la madre que después... tiene derecho a todo... y estos hijos... Te digo, tengo una cantidad de varones de cuarenta años... ahora que están viviendo con la mamá y que no se pueden despegar. Porque de última bueno, por ahí... peor que no, no... no despegan... Esto también... bah... no sé, como que últimamente veo que está... eh... Por eso digo... esto de la madre contra el padre..., la rescatista... Me parece que va en esta línea... es la que rescata (Ema, operadora socio-terapéutica)

Si bien la calificación expresada por Ema en términos de "rescatistas" y/o "abnegadas" tiene connotaciones negativas localmente, lo que se ha podido registrar es que, muchas veces, sin el acompañamiento de las mujeres no usuarias, los usuarios se encontrarían en situaciones de mayor deterioro. 
Estudios previos sobre pobreza, salud y uso de drogas han señalado que los vínculos entre usuarios de drogas y no usuarias de drogas se dan en un contexto de expansión de la intimidad frente a la ausencia y/o negligencia de instituciones, políticas y terapéuticas que operen in situ en los barrios segregados y empobrecidos. Por un lado, las parejas heterosexuales en las que se vinculan varones usuarios de drogas y mujeres no usuarias de drogas, en contextos de vulnerabilidad y pobreza, han sido categorizadas dentro de las lógicas de rescate como aquellas modalidades en las que el amor y el romance constituye una política específica de búsqueda de alivio (Epele, 2010). Por otro lado, se ha documentado de qué manera, a partir de la emergencia e irrupción de la pasta base/paco, se modificaron las modalidades del cuidar de las mujeres-madres no usuarias a hijos usuarios (Epele, 2012). A lo largo del trabajo de campo, se ha podido registrar que el rescate por amor-de pareja- se combina con modalidades de ser rescatado -por las madres-, no siendo siempre estrategias diferenciables. En correspondencia -aunque con múltiples distancias territoriales y culturales- con lo documentado y analizado por Shepper Huges (1997) cuando analiza el amor materno/amor alterno y la muerte de niños en el nordeste de Brasil, "en las barriadas urbanas inhóspitas donde la vida es muy dura [...] la indiferencia materna (ya sea intencional o no) aumenta los riesgos y expone a los niños vulnerables a una muerte prematura" (p. 342). La "abnegación" de las madres de los usuarios de drogas en los sectores pobres del AMBA a la que refería Ema, se localiza en un contexto de ausencia de espacios institucionales específicos en las que tanto la maternidad, el cuidado, la protección y el amparo pueda ser compartido. Específicamente, que se pueda contar con otros que no sean casi exclusivamente las redes de proximidad y las relaciones que se establecen en los tratamientos ambulatorios con los profesionales. Desde las versiones de las mujeres-madres, "dejarlo todo por los hijos" es el correlato a "la desesperación" provocada por la perpetuación de la búsqueda de alivio no encontrado. Al respecto, Palomar Verea (2004: 15) señala que "la sobrecarga del esfuerzo y la responsabilidad de la crianza de hijas e hijos [se produce por] la ausencia de reflexión sobre la maternidad como práctica que compete a toda la sociedad". Tania lee esta situación como la manifestación de los malestares de las mujeres que se encuentran acompañando a los usuarios:

Las madres especialmente... que son tan demandantes. Que quieren internar a los hijos y que generan mucho rechazo en general en los profesionales. Eh... yo puedo entender desde qué lugar lo dice, cómo están atravesados. Una vez un supervisor trabajando con niños me dijo... "El padre, la madre no son enemigos tuyos. Son la madre y el padre de este niño" [...] Acá no hay culpabilidad... habrá responsabilidades... por ahí me ha pasado que algunos entrevistados, algunos casos son como muy densos, muy complejos o... son como muy pegajosos... generalmente madres... que están como muy presentes, entonces se adhieren tanto a vos que le pusiste la oreja..., que las escuchaste, que las orientaste... que empiezan a demandar y a demandar. [...] Lo primero que surge es... hay como una especie de patrón por lo general, ¿no? Digo, por el agotamiento también... las historias de vida, "Pero yo ya hice todo... eh... ya no lo soporto, ustedes tienen que hacer algo" ¿No? “Yo el rol de mamá ya lo cumplí..., llegó acá, tiene 23; 24; 18 años... yo hice todo... entonces ahora ustedes hagan algo, háganse responsables". Y esto genera mucha bronca, porque a veces es dicho de malos modos, digamos... hay un agotamiento, hubo antes todo un proceso de no poder responder a la demanda de ese hijo. Debe estar bastante angustiada para decir: "Yo ya hice todo"..., lo que debe pasar esta mujer para decir eso, ¿no? (Tania, trabajadora social)

Las demandas de las mujeres-madres descriptas como "pegajosas" requieren ser situadas tanto en los modos históricos de trato como en las relaciones e interacciones en las que emergen: los modos en los que han sido tratadas las mujeres de los sectores populares y vincularlas a las tácticas que se despliegan en las instituciones a fin de 
obtener los bienes, servicios. Fonseca (2005), analizando intervenciones sociales en Brasil, señala que "la lógica estatal [...] ve a las familias como culpables por no asumir total responsabilidad por sus miembros, que son rotuladas de 'heterómanas', criticando sus demandas exageradas de ayuda" (p. 58). Por su parte, Lamas -citada por Palomar Veréa (2005: 55) - señala que "los criterios normativos sobre la maternidad hacen recaer la responsabilidad del bienestar del hijo sobre la mujer y dan recetas para el comportamiento maternal". Por otros senderos de análisis, Epele (2013) sostiene que la noción de trato permite corroer la disociación entre un dominio relacional y una especie de esencia subjetiva, ya que posibilita "reconocer tanto la materialidad de lo vincular como su carácter productivo con relación a la subjetividad" (p. 16). En este sentido, el trato hace referencia directa a "aquel proceso vincular complejo que caracteriza y, al mismo tiempo, califica las acciones orientadas hacia otro/s y de los otros con respecto a uno, de modo tal que adquiere ciertos patrones" (p. 16). Las poblaciones desfavorecidas circulan por instituciones públicas en las que los malos tratos y des-tratos no son excepcionales y en los que la insistencia resulta necesaria para la obtención de aquel alivio buscado. Para los profesionales, estas demandas implican situaciones en las que la agresión se presenta para con ellos y también van generando modalidades de trato dentro del tratamiento institucional, aunque -afortunadamente- estos, en gran parte de los casos-, son contemplados como parte intrínseca del padecimiento tanto de quienes acompañan como de quienes consumen drogas.

\section{Entre vaivenes, incertidumbre y perdurabilidad}

Bueno, el tema es que... eh... empezó a consumir cada vez más seguido. Hasta que en febrero... empecé a sospechar que si no era día por medio a algo más seguido. Y... hasta que confirmé que era diario. Y hasta que le digo: "Me siento mal, me hace mal que estés..." A esta altura lo veían dos veces por semana y le insistían con el psiquiatra" Hasta que... después le digo... "Lorenzo... yo me descompongo a la noche, me agarran como ataques de nervios. No sé qué son, pero tiemblo, me dan arcadas, estoy adelgazando mucho". Tiemblo mucho, así, ¿eh? Me tengo que esconder de los chicos si no se quedaron dormidos... [Mirna, pareja de Lorenzo].

Quienes acompañan, sienten. Siguiendo las perspectivas socio-antropológicas que abordan los cuerpos/emociones (Scribano, 2013), no resultan diferenciables -analíticamente- las prácticas, los cuerpos ni las emociones. Los estados del sentir se despliegan en la corporalidad, se localizan en la carne y, según refieren las perspectivas locales de los tratamientos, al ser el centro de atención los usuarios de drogas, se tiende a relegar la atención hacia quienes acompañan. Muestra de ello es que la mayoría de los espacios terapéuticos para usuarios son individuales y los familiares cuentan con espacio grupal. Esta diferenciación se basa en la organización del -escaso- tiempo de trabajo de los -escasos- profesionales, es decir, no se trata de una distribución azarosa, sino que al ser priorizados los usuarios, quedan relegados los malestares de quienes los acompañan. Solo en las situaciones en las que la conflictividad es muy alta -comprometiendo en ocasiones la integridad física, es decir, la supervivencia del paciente-, se otorga espacio terapéutico individual al familiar. Esta preeminencia en la atención no es una elección consciente de los trabajadores institucionales, sino que se encuadra en que tanto tiempo, los profesionales, y las instituciones que abordan a los consumidores problemáticos son escasas (Touzé, 2006; Epele, 2010). Estela, madre de Jaime, lo describe de este modo:

Me da bronca porque... soy una mujer positiva, y una madre luchadora, entonces creo que no me merezco esto, no sé... si es la vida... si es... no sé... te tocó, te tocó. ¿Entendés? Y él... tiene que agradecer que le tocó una madre como yo. Y lucharla 
sola, eso es lo que más bronca me da... [Se le quiebra la voz] de que él no se da cuenta de que... yo también tengo una vida. Eso es lo que me duele que no se dé cuenta. Porque él sabe en otro tratamiento que ha hecho, compañeros... que los padres los han echado y terminaron durmiendo en la calle. "Y sabés que la madre de fulano, qué hija de puta”. Y bueno, pero hay que estar... hay que estar... Este... mismo con el hermano, el hermano en las primeras épocas decía: “iEchalo a la mierda! ¡Es un pelotudo! Echalo mamá, no ves que no sirve, es una bosta, que es una mierda este tipo... que se droga, qué sé yo qué". Después, con los años, con terapia él entendió que es una enfermedad... Pero bueno... y yo siempre le decía: "Cuando vos seas padre lo vas a entender. Mientras tanto vos sos hermano... y lo ves de la vereda de enfrente. Yo lo parí, es otra cosa. Entonces vos lo ves de un lado, y yo que lo tuve adentro, lo miro desde otro lado". Ni los animales... este... dejan a sus hijos. Así que bueno... es un hijo de puta, pero es hijo mío.. [Risa] (Entrevista a Estela)

Los estados emocionales, los sentimientos y afectividades involucradas en el proceso de acompañar, son extremadamente complejos y variantes. Luego de un largo tiempo de conversación con las mujeres y de observación en el grupo de familiares, pude advertir que se encuentran en estados en los que "la desesperación" se vincula directamente a que el otro -hijo o pareja- es el centro de "la preocupación" cotidiana. Resulta necesario considerar, a fin de evitar una lectura heroica o culpabilizadora, que el trauma, por rutinario que sea, no resulta-siempre-naturalizado (Epele, 2010). Tal como resume Estela: "hay que estar". Las mujeres que dedican su tiempo, energía y disposición en acompañar a otro/a, refieren constante cansancio, desgano, agotamiento, miedo corrosivo, "no dar más", "vivir en un infierno", "no saber qué más hacer". "La desesperación" también se vincula con lo que se decodifica como no ser importante para el otro; es decir, no sentirse consideradas por ser quienes acompañan y no ser valoradas por el proceso que llevan a cabo. Estos estados se profundizan cuando piden colaboración y/o presencia a los usuarios y no cuentan con ella. Mirna recuerda que el día de su aniversario de casada, Lorenzo no llegó a su casa ya que estaba con sus amigos:

Eh... me sentí desolada, desamparada mal, me sentí que le di toda mi vida a él y que él no era capaz de venir. Si consume en casa. No se trataba de que deje de consumir. Que venga, que me abrace, que me ayude, que vaya al baño y se drogue [Risa leve]. Que venga, que me abrace. O sea, yo en ese momento lo estaba necesitando... podía drogarse en casa... Y no vino a asistirme. Me sentí no querida, abandonada, desesperada... (Mirna, pareja de Lorenzo)

Las coordenadas en las que se vivencia y experimenta el acompañamiento son plausibles de relación con los dolores crónicos, debido a que el despliegue del complejo de acompañar está cargado de incertidumbre, no-linealidad, constancia, mantenimiento en detrimento de cura y larga perdurabilidad (Good, 1994; Salslavski, 2007; Méndes Diz, 2012). Según lo que se ha podido registrar, cuando de consumos problemáticos de drogas se trata, no son solo los usuarios quienes padecen, sino también sus redes de proximidad. Además, desde las psicoterapias, si bien se da un lugar específico para "poner a trabajar" de aquello que sucede, se tiende a dar ciertas sugerencias para poder resolverlo, que en general, tiene que ver con "darse espacio", "no hacer tanto", "dejarle un espacio al otro". Sin embargo, desde las versiones de las mujeres, el "dejar de hacer" se anuda a "dejarlo ahí... morir", aún cuando no se esté atravesando un período de ingesta intensiva y/o de alta conflictividad a nivel barrial. El acompañamiento se cronifica y, al perpetuarse, también lo hacen los estados del sentir, las prácticas rutinarias y la experiencia constante de estados de alerta. Epele (2010) denominó a este estado como desesperación congelada: "un estado de tal sobrecarga de emociones y tareas que producen inmovilidad, angustia, pérdida de la capacidad 
de acción y reacción, quietud y -en ocasiones- resignación por no poder impedir que los acontecimientos, generalmente trágicos, sucedieran" (p. 261). Es lo que, también, le sucede a Sara:

Es un drama terrible. [...] Primero ves cómo quema su vida y después ves que se está matando. No sé si terminará... cómo... Camino a la locura... me parece. Veo algunas veces personas durmiendo en la calle... Acostados, ¿viste?, en las veredas el bollo así... y me parece que es el futuro de él. Así que trato dentro de buscar el equilibrio permanentemente... Me enojo, le doy, le quito, lo protejo, le digo... Por ahí estoy enojada y no le hablo. Pero él... pienso que lo percibe, entonces anda como quien que no quiere la cosa. [...] A lo mejor son las 2 de la mañana y no vino... ¿Dónde está? No sé. Antes lo salía a buscar... y muchas veces lo encontraba... (Sara, madre de Dante)

Los requisitos de acompañar se vinculan directamente con "tener ganas", "tener aguante", "bancársela", implicando un repertorio de técnicas corporales/emocionales, entre las que se incluyen: "poner límites", "tratar de no llorar", "escuchar lo que le pasa", "preguntarle cómo está", "apoyarlo en los proyectos", entre otras indicaciones promovidas por las terapéuticas. ${ }^{5}$ Así, las psicoterapias adquieren un doble movimiento. Mientras que por un lado se intenta persuadir a las mujeres de "no hacer todo" (que involucra las prácticas), por otro lado, y a la vez, se promueve un acompañamiento (emocional) minucioso y detallista, que implica -en algunos casos- más desgaste y cansancio que las prácticas de protección más extremas. En definitiva, la recurrencia de situaciones complejas exige presencias y acciones que ya saben desplegarlas, porque, en general, ya las han realizado con anterioridad. Las versiones de los profesionales de la salud deslizan que la paciencia es necesaria y que constituye casi un requisito del acompañar. Para las redes de proximidad, sin embargo, no siempre es posible tener paciencia, ya que en la mayoría de los casos, recurren a una institución especializada cuando ya agotaron las instancias de búsqueda de alivio y satisfacción no institucionales. Mirna lo refiere de este modo:

La psicóloga dice que tengo que tener paciencia, que puede ocurrir... que hay que dejar que el tratamiento haga lo suyo, pero que.... todos los días de nuevo, no. El miércoles vino consumido, el jueves vino de laburar a las ocho de la noche, pasó por el súper, trajo mercadería... Pero había consumido.

Mirna, además, señala que se encuentra tensada entre "las ganas de acompañarlo por amor" y "las ganas de mandarlo a la mierda por forro", tensión que poco tiene que ver con estados inmutables, sino que en un movimiento y vaivén constantes, se dirime lo que "está dispuesta a hacer". Disposición, que es el momento en el que se llega al "límite" -absolutamente variable dependiendo de si se trata de hijos o parejas, así como también de la frecuencia de consumo-, se vivencia como de no retorno -y no por ello inamovible ni perdurable-.

El acotamiento de las redes vinculares se vivencia como un costo del acompañar, sea por una disminución de las redes de proximidad de quien acompaña o sea porque compartir con otros implica, en ocasiones, más agotamiento y/o juicio moral de los próximos, como en el caso de Estela:

-Para qué cargarte más en la mochila de ir explicando... o sosteniendo, o conteniendo... No, no, bastante tengo que aguantar, sostener y contener en casa. Y el resto de la familia qué sabe, bueno, el que quiere preguntar, pregunta y el que no, está todo bien. [Risa leve] Es una carga muy pesada.
5 Si bien la categoría nativa de "aguante" ha sido detalladamente documentada y analizada en hinchadas de fútbol por Garriga y Alabarces (2008), también la ha delimitado Epele (2010) en usuarios de drogas y Del Mónaco (2013) en personas que viven con dolor crónico. Sin embargo en el trabajo de campo realizado, la noción de "aguante" se expandió principalmente entre las mujeres que se encuentran "acompañando" a los usuarios, adquiriendo otros matices diferenciables a lo que han elaborado las investigaciones precedentes, debido a que cobra preeminencia el "aguante emocional" sobre el "aguante corporal". 
- ¿Y cómo es estar en este estado de angustia? Que no siempre estoy así, ¿eh? Lo hablo con personas que son afines al tema y que... entienden. Porque otra gente es al pedo que le hables porque no te entienden. Gente que es ignorante que no... "Ah, bueno, pero yo le hubiera dado una patada en el culo" Sí, bueno... hay que verlo, cuando te toque a vos de cerca, contame. Ojalá nunca te pase, pero... nunca escupas para arriba... En la familia no hubo un caso que sepamos. Que sepamos... ese es el tema, ¿viste?, porque también... Hemos sabido de otras debilidades pero... no de adicciones declaradas, qué sé yo... No. Es una carga, es una mochila muy pesada para llevar. Pero bueno, hay que ponerle una de cal y una de arena. El tema que se juntan más una de cal y una de arena para sostener, cagamos... Yo digo por algo Dios me hizo grandota y fuerte, porque sino... Y sí... la verdad... Tengo una amiga que me contiene un montón... y este... es con la que más puedo hablar. Y este... pero bueno, no con todo el mundo podés hablar. No con todo el mundo podés hablar de la misma manera, porque no te saben entender. Te pueden dar un abrazo, pero en el fondo... como todo, ¿viste?, si no se palpa... no lo podés entender (Estela, madre de Jaime)

Como señala Estela, el achicamiento del mundo vincular no solo afecta a los usuarios, sino también a quienes los quieren y, de este modo, se condensa, y perpetúa en quienes los acompañan estados del sentir -también- saturados de intensidad, rebalsados de cargas.

\section{A modo de cierre: presencias enrevesadas}

Si bien en las últimas décadas los estudios acerca de los usos intensivos de drogas de baja calidad y de las terapéuticas que buscan abordarlos se han acrecentado, queda aún mucho por pensar y por hacer para colaborar con generar alivios acordes a los malestares. Uno de los aspectos que han recibido poca atención es, justamente, el rol de las redes de proximidad en los tratamientos que buscan reducir y/o suprimir la ingesta de tóxicos: los cuerpos/emociones de las mujeres que ocupan su tiempo en acompañar a sus seres queridos. A lo largo de estas páginas se ha sostenido que la convocatoria a la familia desde los tratamientos ambulatorios públicos sobre los usos de drogas operan como una sinécdoque que vela la delegación del cuidado, control y protección hacia las mujeres vinculadas a los usuarios por relaciones de parentesco: mujeres (madres y parejas). También se ha señalado que estas presencias están vinculadas a los idearios de familia nuclear y de buena maternidad-que por más que hayan sido y continúen siendo criticadas política y analíticamente no dejan de operar-. Luego, se ha realizado un recorrido sobre dos de las caracterizaciones expertas -principalmente aquellas provenientes de las perspectivas psi- acerca de las modalidades que asumen los despliegues de las maternidades con respecto a los usuarios de drogas: el "abandono" y el "pegoteo". Y, posteriormente, se ha reparado en las afecciones y estados del sentir de las mujeres que acompañan, que distan de ser plenos y planos, sino que, por el contrario, son contrariados, tensos y complejos.

Bien lejos de las lecturas tanto heroicas como culpabilizadoras acerca de las redes de intimidad-especialmente de las mujeres-madres y parejas heterosexuales-, los estados del sentir señalados por las entrevistadas dan cuenta de que acompañar a usuarios intensivos de cocaínas de mala calidad implica desgaste, cansancio, desesperación, miedo y amor. Así, la disposición hacia el acompañamiento -necesario, en ocasiones, para garantizar la supervivencia de sus seres queridos-implica complejidades corporales/emocionales que serían relevantes de considerar tanto para las políticas sociales que buscan abordar a las poblaciones desfavorecidas -no solo a los usuarios, 
sino también a quienes los quieren- como para las reflexiones analíticas que buscan esclarecer los procesos que condicionan sus vidas.

Durante el tiempo en el que desplegué el trabajo de campo que sustenta este artículo, y a diferencia de ciertos saberes del sentido común como también distante de ciertas perspectivas analíticas, observé que estas conflictividades han quedado a la disposición -o no- de los profesionales de la salud y a lo que junto con las redes de proximidad pueden -o no- hacer para aliviar los padecimientos asociados a las ingestas intensivas de drogas -sea por su consumo directo o por acompañar a alguien que lo haga-. Como se ha insinuado insistentemente, no se trata pues de cuestiones diádicas, sino que ciertos imperativos morales subyacen al despliegue de los acompañamientos y de quiénes lo realizan en la cotidianidad de sus vidas. Estas configuraciones, si bien son tomadas por parte de los profesionales de la salud, no son consideradas/ problematizadas -en general- en los diseños de las políticas públicas que, en parte, abonan ese ideario de que la familia y en particular las mujeres-madres y parejas, pueden ser una suerte de "solución" sin considerar que también ellas sufren y hacen y sienten-como todos- lo que pueden. Así, en ocasiones, los tratamientos ambulatorios como parte de las política pública a la vez que intenta -en ocasiones y dependiendo de quienes en ellas trabajan- generar mecanismos de protección, desliza transformaciones en los modos de vinculación que omiten las condiciones económico-políticas de los consumos y las relaciones que se establecen a partir de allí. 


\section{Bibliografía}

"Achilli, Elena Libia (2005). Investigar en Antropología Social. Los desafíos de transmitir un oficio, Buenos Aires, Laborde.

" Aguirre, Rosario (2005). "Los cuidados familiares como problema público y objeto de políticas", en Políticas hacia las familias, protección e inclusión sociales, Santiago de Chile, Irma Arriagada.

" Candil, Ana Laura (2016). "Acompañar a usuarios intensivos de drogas: el papel de las redes de proximidad en los tratamientos ambulatorios", Antípoda, núm. 26, septiembre-diciembre, p. 41.

»Auyero, Javier y Berti, María Fernanda (2013). La violencia en los márgenes. Una maestra y un sociólogo en el conurbano bonaerense, Buenos Aires, Katz.

»Ayres, José Ricardo C. M. (2004). Cuidado e reconstrução das práticas de saúde, San Pablo, UNESP.

» Bonet, Octavio y Tavares, Fátima (2007). “O cuidado como metáfora nas redes das práticas terapêuticas". En Razões públicas para a integralidade em saúde: o cuidado como valor. Río de Janeiro, Editorial do Centro de Estudos e Pesquisa em Saúde Colectiva.

"Castaño, Guillermo A. (2000). "Cocaínas fumables en Latinoamérica", Adicciones, vol. 12, núm. 4, pp. 541-550.

»Castilla, Victoria (2013). “Madres, ciencia y burocracia”, Avá, núm. 22, junio, pp. 209-228.

»Castilla, María V.; Olsen, María C. y Epele, María E. (2012). Dinámicas familiares, prácticas de cuidado y resolución de problemas asociados al consumo intensivo de pasta base/paco en Buenos Aires, Argentina. Antípoda, núm. 14, enero-junio, pp. 209-229.

»Del Mónaco, Romina (2013). “Autocuidado, adherencia e incertidumbre: tratamientos biomédicos y experiencias de pacientes en el dolor crónico de la migraña”, Salud Colectiva, vol. 9, núm. 1, abril, pp. 65-78.

»Domínguez Mon, Ana (compiladora) (2012). “Agencia y cuidados en personas que viven con enfermedades crónicas no trasmisibles”, Documentos de Trabajo, núm. 6o, Instituto Gino Germani, Facultad de Ciencias Sociales, Universidad de Buenos Aires.

»Durham, E. (1988). “Familia y reproducción humana” en Neufeld, M. et al. (comps.) Antropología social y política. Hegemonía y poder: el mundo en movimiento, Buenos Aires, Eudeba.

»Epele, María (2010). Sujetar por la herida. Una etnografía sobre drogas, pobreza y salud, Buenos Aires, Paidós.

" (2012). "Sobre o cuidado de outros em contextos de pobreza, uso de drogas e marginalizacao", Mana, vol. 18, núm. 2, agosto, pp. 247-268.

》- (2013). "Padecer, cuidar y tratar. Estudios socio-antropológicos sobre consumo problemático de drogas”, Buenos Aires, Antropofagia.

»Fonseca, Claudia (2005). "Concepcoes de familia e práticas de intervencao: uma contribucao antropológica”, Saude e Sociedade, vol. 14, núm. 2, agosto, pp. 50-59. 

racoes”. Cadernos Pagu, núm.29, julio-diciembre, pp. 9-35.

» Fuller, N. (2001). "Maternidad e identidad femenina: relato de sus desencuentros”, en Burak, S. (comp) Adolescencia y Juventud en América Latina, Cartago, Libro Universitario Regional.

» Garriga Zucal, José y Alabarces, Pablo (2008). “El “aguante”: una identidad corporal y popular", Intersecciones en Antropología, núm. 9, pp. 275-289.

»Good, Byron J. (1993). Medicine, rationality and experience. An anthropological perspective, Cambridge, Cambridge University Press.

"Guber, Rosana ([2001] 2012). La etnografía. Método, campo y reflexividad, Buenos Aires, Siglo XXI.

» Harvey, David ([1998] 2009). Breve historia del neoliberalismo, Madrid, Akal.

» Jelin, Elizabeth (2010). Pan y afectos. La transformación de las familias, Buenos Aires, Fondo de Cultura Económica.

"Kessler, Gabriel (2008). "Las transformaciones en el delito juvenil en Argentina y su interpelación a las políticas públicas” en Potthast, B. et. al. (eds.) Ciudadanía vivida, (in)seguridades e interculturalidad, Buenos Aires, Nueva Sociedad.

»Kleinman, A. y Benson, P. (2004). "La vida moral de los que sufren enfermedad y el fracaso existencial de la medicina” en Bayés, Ramón (Ed.) Dolor y sufrimiento en la práctica clínica, Barcelona, Fundación Medicina y Humanidades Médicas.

» Maffia, Diana (2014). "Géneros, identidades y familias diversas. Desafíos al derecho a la igualdad”, Voces en el Fénix, núm. 32, marzo, pp. 6-14.

»Mendes Diz, Ana M. (2012) “Las enfermedades crónicas. Un nuevo paradigma de abordaje desde lo médico y lo social" en Dominguez Mon, A., Mendes Diz, Ana M., Schwarz, P., Rosas, M., Camejo, M., y Caruso, P. Agencias y cuidados en personas que viven con enfermedades crónicas no transmisibles, Documentos de Trabajo, núm. 6o, Buenos Aires, IIGG.

"Mol, Annemarie (2008). The Logic of Care. Health and the problem of patient choice, Londres, Routledge.

"Murillo, Susana (2013). "La estrategia neoliberal y el gobierno de la pobreza. La intervención en el padecimiento psíquico de las poblaciones”, Voces en el Fénix, vol. 4, núm. 22, marzo, pp. 70-77.

» Navarro, F. y Rico, M. (2013). "Cuidado y políticas públicas: debates y estado de situación a nivel regional", en Pautassi, L y Zibecchi, C. (coords.). Las fronteras del cuidado. Agenda, derechos e infraestructura, Buenos Aires, Biblos.

»Palomar Verea, Cristina (2004). "Malas madres: la construcción social de la maternidad", Proyecto de investigación del Centro de Estudios de Género de la Universidad de Guadalajara. núm. 22, pp. 35-67. (2005) . "Maternidad: historia y cultura", La ventana,

"Pautassi, L. y Zibecchi, C. (2013). Las fronteras del cuidado: agenda, derechos e infraestructura, Buenos Aires, Biblos.

" Rodríguez Enríquez, Corina (2012). "La cuestión del cuidado: ¿El eslabón perdido del análisis económico?”, CEPAL, núm. 106, abril, pp. 23-36. 
》Saslavski, Liliana C. (2007). ¿Por qué no se cura (todavía) la diabetes? Un abordaje antropológico de la enfermedad considerada la epidemia del siglo XXI, Buenos Aires, Antropofagia.

»Schwarz, Patricia (2012). "Las mujeres y el cuidado en las enfermedades crónicas. Entre autonomía y la heteronomía” en Domínguez Mon, A., Méndes Diz, Ana M., Schwarz, P., Rosas, M., Camejo, M., y Caruso, P., Agencias y cuidados en personas que viven con enfermedades crónicas no transmisibles. Documentos de Trabajo, núm. 6o, Buenos Aires, IIGG.

"Scribano, Adrian (2013). "Sociología de los cuerpos/emociones", Revista Latinoamericana de Estudios sobre Cuerpos, Emociones y Sociedad, vol. 10, núm. 4, diciembre-marzo, pp. 93-113.

» Shepper-Huges, Nancy (1997). La muerte sin Ilanto. Violencia y vida cotidiana en Brasil, Barcelona, Ariel.

»Stolkiner, Alicia (2004). "Las familias y la crisis. Cuestiones de infancia”, UCES, núm. 8, marzo, pp. 135-149.

» Tarducci, Mónica (2013). “Adopción y parentesco desde la antropología feminista”, La ventana, vol. 4, núm. 37, enero-junio, pp. 106-145.

»Topalov, C. (1979). La urbanización capitalista, México, Grijalbo.

" Torrado, Susana (2007). "Hogares y familias en América Latina”, Revista Latinoamericana de Población, vol. 1, núm. 1, junio-diciembre, pp. 57-65.

»Torres Dávila, María S. (2004). Género y discapacidad: más allá del sentido de la maternidad diferente, Quito, Abya-Yala.

» Touzé, Graciela (organizadora) (2006). Saberes y prácticas sobre drogas: el caso de la pasta base de cocaína, Buenos Aires, Intercambios Asociación Civil: Federación Internacional de Universidades Católicas.

» Tronto, Joan (1993). Moral Boundaries. A political argument for an ethic of care, Nueva York, Routledge.

"Voria, María A. (2015). “Dilemas analíticos en torno de la categoría de cuidado”, La Ventana, vol.5, núm.41, pp. 113-152. 